\title{
Penggunaan Bahasa Sunda Pada Pembelajaran Bahasa Inggris
}

\author{
The Use of Bahasa Sunda in English Language Teaching
}

\author{
Lystiana Nurhayat Hakim \\ Pipit Prihartanti Sugiarto \\ Universitas Perjuangan Tasikmalaya, Tasikmalaya \\ tianaghea@gmail.com
}

Riwayat Artikel: Dikirim 17 Maret 2020; Diterima 22 Juni 2020; Diterbitkan 30 Juni 2020

\begin{abstract}
ABSTRAK
Bahasa Sunda merupakan bahasa pertama masyarakat Jawa Barat dan tidak sedikit orang yang menggunakan bahasa sunda diberbagai aspek kehidupan, salah satunya dalam pendidikan.Sekarang ini banyak dijumpai peomena penggunaan bahasa sunda sebagai bahasa pertama dalam pembelajaran bahasa Inggris. Beberapa ahli memperdebatkan penggunaan bahasa pertama dalam pengajaran bahasa asing yang dinilai akan menganggu makna, tujuan, dan fungsi bahasa Inggris. Oleh karena itu penting sekali bagi peneliti untuk melakukan penelitian dengan tujuan untuk mencari tahu fungsi dan alasan penggunaan bahasa sunda dalm pembelajaran bahasa Inggris dan mencari tahu persepsi siswa terhadap penggunaan bahasa sunda dalam proses belajar mengajar bahasa Inggris. Penelitian ini menggunakan studi kasus dimana tiga orang guru bahasa Inggris dan 20 orang siswa menjadi subjek penelitian. Instrumen penelitian yang dipakai ialah obesrvasi, wawancara, dan kuesioner. Hasil dari penelitian ini ialah Bahasa Sunda digunakan dalam pemberian instruksi, pemberian motivasi, penjelasan kosakata dan materi ajar, menunjukan ekspresi marah, kecewa, dan bahagia, penggunaannya dilakukan dengan tujuan untuk memberikan rasa nyaman dan kemudahan ketika berkomunikasi dan berinteraksi baik dengan guru maupun teman sejawat, serta untuk menghindari kesalahpahaman makna baik dalam komunikasi biasa ataupun dalam pemeberian materi ajar. Selain itu hasil dari penelitian ini ialah siswa menunjukan persepsi positif terhadap penggunaan Bahasa Sunda dalam pembelajaran Bahasa Inggris di kelas.
\end{abstract}

Kata kunci: Bahasa Ibu, Pembelajaran, Bahasa Asing 


\begin{abstract}
The purposes of this research were to investigate learners' perception toward the use of Bahasa Sunda in English class, the function of Bahasa Sunda in EFL class, and the reasons of using Bahasa Sunda in English class. The participants were 20 students in one of Senior High School in West Java, Indonesia. This research was designed in qualitative study by distributing a questionnaire and conducting observation and interview as the data collection techniques. The findings showed that Bahasa Sunda used for giving instruction and motivation, explaining vocabulary and teaching materials, and showing several expressions of angry, disappointed, and happy. In addition, the purposes of using Bahasa Sunda in English language teachings are to create comfort atmosphere, to help students in communicating and interacting with the teachers and friends, and to avoid misunderstanding both in verbal communication and in giving teaching materials. Furthermore, they also welcome the L1 (Bahasa Sunda) and they have positive perception toward the use Bahasa Sunda in English language learning. In view of this, the use of both their L1 and L2 should be balanced.
\end{abstract}

Keywords: EFL student teachers; English teaching and learning; first language; foreign language

\title{
PENDAHULUAN
}

Bagi sebagian siswa di Jawa Barat belajar Bahasa Inggris merupakan hal yang sangat menakutkan.Terkadang mereka merasa frustasi dan tegang untuk belajar Bahasa Inggris. Oleh karena itu beberapa guru Bahasa Inggris menggunakan bahasa pertama yaitu bahasa sunda dalam kegiatan pembelajaran dengan tujuan agar siswa menjadi lebih mengerti akan materi yang diajarkan.

Bahasa pertama ialah bahasa yang diperoleh seseorang secara alami dari waktu ke waktu dari lingkungan tempat tinggalnya. Dengan kata lain bahasa pertama ialah bahasa ibu atau bahasa yang diperoleh seseorang pertama kali. Selain itu (Khati, 2012) menyatakan bahwa bahasa pertama ialah bahasa yang diproduksi seseorang sejak kecil dan dapat menggunakannya dengan nyaman diberbagai keadaan.

(Harmer, 2007) percaya bahwa penggunaan bahasa pertama dalam pembelajaran tidak dapat dihindari dan merupakan hal yang lumrah terjadi pada interaksi kelas. Pada umumnya penggunaan bahasa pertama di kelas Bahasa Inggris ialah untuk menjembatani gap yang terjadi anatara siswa dan guru pada saat interaksi, contohnya seorang guru menerjemahkan ke dalam bahasa pertama mereka saat mereka tidak paham dengan instruksi yang diberikan. Akan tetapi penggunaan bahasa pertama dalam pembelajaran Bahasa Inggris harus dipertimbangkan sebaik mungkin agar tidak terjadi kesalahan dalam pemerolehan bahasa kedua bagi siswa. 
Penggunan bahasa pertama pada pembelajaran Bahasa asing merupakan isu yang sangat menarik untuk diteliti.Beberapa teori percaya bahwa hal tersebut memiliki kontribusi yang baik dalam pembelajaran bahasa asing.(Harmer, 2007) dan (Brown, 2007) menganggap bahwa menggunakan bahasa pertama akan bermanfaat dan berguna untuk memfasilitasi dan mendukung proses belajar mengajar. Hal ini didukung dari hasil penelitian yang dilakukan oleh (Alshehri, 2017) yang mengatakan bahwa sebagaian besar guru menggunakan bahasa pertama untuk menjelaskan kosakata, mengklarifikasi makna kalimat yang sulit dipahami, serta membangun hubungan yang baik dengan siswa, mereka juga percaya bahwa bahasa pertama akan meningkatkan pembelajaran bahasa asing.

Penggunaan bahasa pertama juga dilakukan untuk menjelaskan tata bahasa yang sulit, kata yang ambigu, instruksi yang panjang, untuk memberikan masukan dan untuk mengecek kepahaman siswa (Buyukyazi, 2011). (Zakaria, 2017) juga berpendapat bahwa dalam pembelajaran bahasa Inggris sebagai bahasa asing guru mengalami kesulitan untuk memfasilitasi belajar siswa kecuali adanya interfensi atau penggunaan bahasa pertama.Sebaliknya, selain itu (Ghorbani, 2011) berpendapat bahwa siswa dapat meningkatkan pemahaman dan kemampuan berbicara Bahasa Inggris secara efektif jika menggunakan bahasa pertama. Penggunaan bahasa pertama juga diyakini dapat membantu siswa memperoleh pengetahuan yang dibutuhkan dan untuk memberikan solusi akan ketidakpahaman mereka dalam belajar bahasa Inggris.

Beberapa siswa merasa pembelajaran bahasa Inggris sulit dan mereka mengalami masalah dalam mengemukakan ide, pendapat, dan komentar dengan menggunakan bahasa Inggris dalam pembelajaran, maka mereka lebih memilih untuk menggunakan bahasa pertama untuk berinteraksi dengan guru dan temannya dikelas. Akan tetapi penggunaan bahasa pertama dalam pembelajaran Bahasa Inggris masih diperdebatkan apakah diperlukan dalam pembelajaran Bahasa Inggris atau tidak dengan alasan tidak semua instruksi dalam bahasa Inggris dapat diterjemahkan ke dalam bahasa pertama langsung, artinya guru harus mempertimbangkan makna dan tata bahasa yang diterjemahkan. Dan hal ini tentunya akan sangat memakan banyak waktu dan ditakutkan akan membuat proses belajar mengajar menjadi tidak efektif.

Cristina dan Voicu (2012) mengidentifikasi beberapa kekurangan dari penggunaan bahasa pertama dalam pembelajaran bahasa Inggris. Pertama, penggunaan bahasa pertama yang terlalu berlebihan mengakibatkan kebiasaan buruk bagi guru dan siswa pada proses pembelajaran, interaksi di kelas dengan menggunakan bahasa pertama akan dirasa nyaman oleh siswa sehingga mereka tidak mau membiasakan berbicara dengan bahasa Inggris. Kedua, bahasa pertama akan membuat siswa bingung dan salah paham ketika mereka menggunakan bahasa Inggris, hal ini dikarenakan terdapat ketidaksesuaian pemilihan kata yang berasal dari bahasa pertama ke bahasa Inggris, begitupun sebaliknya. Ketiga, ketika guru mengggunakan bahasa pertama dalam 
pembelajaran bahasa Inggris maka akan menimbulkan pola kalimat yang tidak benar.

Melihat pada kelebihan dan kekurangan penggunaan bahasa pertama dalam pembelajaran bahasa Inggris maka penelitian terkait tujuan dan alasan penggunaan bahasa pertama tersebut perlu dilakukan, selain itu mencari tahu pandangan siswa akan penggunaan bahasa pertama dalam pembelajaran bahasa asing juga sangat diperlukan untuk mencari langkah yang harus dilakukan oleg guru selanjutnya dalam mengajar Bahasa Inggris. Hal ini tidak dilakukan oleh peneliti sebelumnya maka penelitian ini bertujuan untuk mengidentifikasi fungsi penggunaan bahasa sunda dalam pembelajaran bahasa Inggris, mengidentifikasi alasan penggunaan bahasa sunda dalam pembelajaran bahasa Inggris, dan mencari tahu persepsi siswa terhadap penggunaan bahasa sunda dalam proses belajar mengajar bahasa Inggris.

Penelitian terkait penggunaan bahasa ibu atau bahasa pertama pada pembelajaran bahasa asing telah dilakukan oleh beberapa peneliti terdahulu diantaranya ialah (Romero \& Manjarres, 2017), (Pardede, 2012)(Zakaria, 2017), dan (Alshehri, 2017).

Khati (2012) mengidentifikasi peran bahasa Nepal sebagai bahasa ibu atau bahasa pertama siswanya pada pembelajaran bahasa asing, hasil penelitiannya menunjukkan bahwa peran bahasa pertama mereka ialah untuk menolong siswanya agar lebih nyaman dan percaya diri, untuk mengecek pemahaman, dan untuk menerjemahkan kosakata.Selain itu, Pardede (2013) menyimpulkan bahwa jika guru menggunakan bahasa pertama maka penjelasan grammar, pemberian instruksi, diskusi dan pengecekan pemahaman siswa menjadi lebih efektif. Selanjutnya penelitian Alshehri (2017) juga membuktikan bahwa bahasa pertama atau bahasa ibu digunakan untuk menjelaskan kosakata, mengklarifikasi makna yang tidak jelas, dan membangun interaksi dan kerjasama dengan siswa. Akan tetapi, hasil penelitian dia juga menunjukkan bahwa guru memiliki pandangan untuk memaksimalkan penggunaan bahasa asing (Bahasa Inggris), mereka pun percaya bahwa Bahasa Inggris harus menjadi bahasa utama pada proses pembelajaran, serta guru menjadi model bagi siswa dalam menggunakan bahasa Inggris.Hal ini sesuai dengan penelitian yang dilakukan Zakaria (2017) yang menunjukkan bahwa penggunaan bahasa pertama oleh guru membantu ketika menimbulkan keamanaan, menyampaikan kata, memeriksa pemahaman, dan menjelaskan pola tata bahasa.Dia juga menemukan beberapa siswa yang merasa malu, takut melakukan kesalahan serta cemas dalam menggunakan bahasa asing. Oleh karena itu bahasa ibu atau bahasa pertama mereka membantu membuat mereka nyaman dan memperoleh kepercayaan diri, sehingga motivasi belajar mereka tidak menurun.

Romero \& Manjarres (2017) juga meneliti akan pengaruh bahasa pertama pada pembelajaran bahasa. Hasil penelitian mereka menunjukan bahwa kebiasaan siswa dalam menggunakan bahasa ibu terbawa dalam pembelajaran bahasa asing, contohnya dalam menggunakan tanda baca dalam 
menulis, membuat kalimat yang secara struktur bahasa kurang tepat (bahasa ibu yang diterjemahakan secara langusng pada bahasa asing), serta dalam melafalkan kata dengan intonasi, tekanan, bahkan dialek nya bahasa ibu mereka.

Bahasa pertama merupakan bahasa yang pertama kali diperoleh seseorang, sedangkan bahasa kedua diperoleh atau dipelajari setelah seseorang menguasai bahasa pertama. Pemerolehan bahasa pertama merupakan proses dimana seseorang mendapatkan bahasa ibunya, dan hal ini tejadi mulai masa kanak-kanak hingga dewasa (Setyadi \& Salim, 2013). Berbeda dengan pemerolehan bahasa pertama, seseorang memperoleh bahasa kedua melalui proses pembelajaran dan secara sadar dipelajari baik di kelas maupun di luar kelas. Pemerolehan bahasa pertama dapat menjadi pembanding yang baik sebagai titik tolak untuk menjelaskan pemerolehan bahasa kedua. Selain itu, pada pemerolehan bahasa pertama, anak umumnya melalui beberapa tahapan akuisisi bahasa sehingga pemerolehan bahasa kedua juga memerlukan waktu untuk proses internalisasi (Maharani \& Astuti, 2018).

Seperti yang terjadi di Jawa Barat dimana bahasa Sunda merupakan bahasa pertama masyarakatnya mempengaruhi pemerolehan bahasa asing yaitu bahasa Inggris. Mata Pelajaran bahasa Inggris pun telah diajarkan sejak anak duduk di Sekolah Dasar hingga SMA, akan tetapi hasil yang diperoleh tidak sebanding dengan lamanya proses pembelajaran bahasa Inggris. Hal ini dikarenakan banyak yang mengasumsikan bahwa bahasa asing hanya dipelajari di dalam kelas saja dan tidak untuk digunakan sehari-hari (Syahid, 2015).

Seperti yang telah dipaparkan sebelumnya bahwa penggunaan bahasa pertama pada pembelajaran bahasa asing memiliki dampak positif dan negatif. Selain dapat memberikan kenyamanan, kemudahan, serta kejelasan pada siswa hal ini juga dapat mengakibatkan siswa terbiasa menggunakan bahasa pertama mereka sehingga percaya diri dan tingkat penguasaan bahasa keduanya pun rendah. Maka dari itu penelitian ini dilakukan untuk mengidentifikasi alasan, fungsi, serta persepsi siswa dalam menggunakan bahasa pertama pada pembelajaran bahasa asing.

\section{METODE}

Penelitian ini menggunakan desain kualitatif yaitu studi kasus yang ditujukan untuk mencari tahu fungsi dan alasan penggunaan bahasa pertama tersebut serta mencari tahu pandangan siswa akan penggunaan bahasa pertama dalam pembelajaran bahasa Inggris. Subjek penelitian ini adalah 3 orang guru Bahasa Inggris dan 20 siswa di salah satu sekolah di Jawa Barat.

Untuk menjawab semua pertanyaan penelitian, peneliti menggunakan kuesioner, wawancara, dan observasi sebagai instrumen penelitian. Kuesioner yang digunakan terdiri dari 10 pernyataan, kuesioner ini diberikan kepada siswa untuk mencari tahu pandangan siswa terhadap penggunaan bahasa 
sunda dalam pembelajaran bahasa Inggris. Untuk mencari tahu alasan penggunaan bahasa pertama dalam pembelajaran bahasa Inggris, penulis menggunakan wawancara. Wawancara dilakukan kepada 3 orang guru dengan menggunakan 5 butir open-ended questions dimana guru dapat menjawab pertanyaan dengan bebas dan tidak terbatas, dengan demikian peneliti dapat menggali lebih dalam informasi pada guru terkait dengan alasan penggunaan bahasa pertama dalam pembelajaran Bahasa Inggris. Selanjutnya obesrvasi digunakan peneliti untuk melihat fungsi bahasa pertama dalam pembelajaran Bahasa Inggris. Obesrvasi dilakukan sebanyak 4 kali. Peneliti mengamati semua proses pembelajaran dari awal hingga akhir pembelajaran. Selain menggunakan observation checklist, peneliti jugan menngunakan catatan (field note) untuk mencatat hal-hal yang terjadi selama proses kegiatan belajar mengajar.

Analisis data pada penelitian ini menggunakan model interaktif (Miles, Huberman, \& Saldana, 2014), kegiatan analisis terdiri dari tiga alur kegiatan yang terjadi secara bersamaan, yaitu reduksi data, penyajian data, dan penarikan kesimpulan atau verifikasi. Pada tahap reduksi data, data diperoleh dari hasil observasi terkait penggunaan Bahasa sunda dalam pembelajaran Bahasa Inggris, kuesioner pada siswa terkait persepsi siswa akan penggunaan Bahasa Sunda dalam pembelajaran Bahasa Inggris, dan wawancara terkait alasan dan fungsi penggunaan Bahasa Sunda dalam pembelajaran Bahasa Inggris, ketiga data tersebut kemudian dirangkum, dipilih dan dikategorikan serta data difokuskan pada hal-hal yang sesuai dengan tujuan penelitian. Tahap selanjutnya ialah penyajian data berupa narasi catatan lapangan, narasi catatan hasil wawancara, dan tabel hasil kuesioner, kemudian tahap terakhir ialah membuat kesimpulan dan menjawab pertanyaan penelitian dari data yang telah direduksi dan disajikan.

\section{HASIL DAN PEMBAHASAN}

Seperti yang telah dipaparkan sebelumnya bahwa tujuan penelitian ini ialah untuk mencari tahu fungsi Bahasa Sunda dalam pembelajaran Bahasa Inggris, alasan pengginaan Bahasa Sunda dalam pembelajaran Bahasa Inggris, dan persepsi siswa terhadap penggunaan fungsi Bahasa Sunda dalam pembelajaran Bahasa Inggris. Dengan menggunakan observasi, kuesioner, dan wawancara sebagai instrumen penelitian, maka penelitian ini menghasilkan beberapa temuan sebagai berikut:

\section{a. Fungsi Bahasa Sunda dalam pembelajaran Bahasa Inggris:}

Data observasi dan wawancara yang telah dilakukan menunjukkan bahwa sebagian besar fungsi penggunaan Bahasa Sunda dalam pengajaran Bahasa Inggris ialah untuk memberikan instruksi atau perintah.Berikut merupakan contoh instruski atau kalimat perintah yang diucapkan siswa dan guru. 
[1]

Guru : Clean the whiteboard, enggal hapus borna!

(Clean the whiteboard, cepat bersihkan papan tulisnya!)

Siswa : Nu piket, Adi tuh hapus borna geuwat! (Yang piket kelas hari ini, Adi cepat bersihkan papan tulisnya!)

Pada data 1 diatas terlihat bahwa guru langsung menjelaskan kalimat perintah kedalam bahasa Sunda setelah berbicara menggunakan bahasa Inggris, siswa pun meresponnya dengan bahasa Sunda dan siswa menyuruh temannya yang piket kelas untuk membersihkan papan tulis menggunakan bahasa sunda.

[2]

Guru : Deni, Can you come forward!

Deni : Naon bu?

(apa bu?)

Guru : Kadieu kapayun!

(kesini kedepan!)

Data 2 menunjukkan siswa tidak paham akan instruksi guru yang menyuruhnya untuk kedepan kelas, siswa pun merespon dengan bahasa sunda dan guru langsung memberi perintah kedepan dengan menggunakan bahasa sunda juga.

[3]

Siswa A : ssst...garandeng geura ih, repeh!

(ssst... jangan berisik)

Siswa B : hey barudak, tuh si ibu nempokeun, ngalobrol wae tuda!

(hai, teman-teman, bu guru lihatin kita, jangan ngobrol terus!)

[4]

Siswa D : bu, jelaskeun deui geura, bisi abi salah!

(bu, tolong dijelaskan kembali, saya takut salah!)

Guru

: With my pleasure!

Pada data 3 dan 4 pemberian instruksi atau perintah dilakukan tidak hanya antara siswa dan guru melainkan juga antara siswa dan siswa.Pada umumnya siswa di SMPN Satu Atap 1 Cipaku lebih cepat dan paham jika kalimat perintah untuk melakukan sesuatu dalam kegiatan belajar mengajar Bahasa Inggris menggunakan Bahasa Sunda.

Fungsi yang kedua ialah untuk memberikan motivasi pada proses belajar mengajar. Dengan menggunakan Bahasa Sunda pemberian motivasi 
dari guru ke siswa dan dari siswa ke siswa lainnya lebih berhasil ditambah dengan menggunakan bahasa Sunda proses pemberian motivasi pun mudah dipahami.

[5]

Guru : Den, where is your homework?

Siswa $\quad:$ PR bu?

Guru :yes, your homework.

Siswa : tapi da padu bu ngerjakeuna. (tapi saya asal mengerjakannya bu)

Guru : : Good try. But not quite right.

Siswa : hese bu (susah bu)

Guru : sing rajin maca, sok cobian deui gera! (kamu harus rajin baca, coba kerjakan lagi ya!)

Siswa : uhun bu

(baik bu)

Data 5 menunjukan bahwa guru memberikan motivasi pada siswa agar membaca dan mengerjakan lagi tugasnya. Guru menggunakan bahasa Sunda dalam memberikan motivasi pada siswa tersebut.

Fungsi yang ketiga ialah untuk memberikan penjelasan kosakata, kalimat, serta pelafalan kata dalam Bahasa Inggris. Ketika proses belajar mengajar berlangsung dan siswa ada yang tidak paham dengan apa yang diajarkan guru, maka secara langsung guru menerjemahkan materi tersebut ke dalam Bahasa Sunda, termasuk juga menerjemahkan kosa kata langsung ke Bahasa Sunda.

[6]

Guru : What is the purpose of the text? Jadi tujuan teks ieu naon? (What is the purpose of the text? Jadi apa tujuan teks ini?

$[7$

Guru : Purbaratu's fiance. Tunanganna Purbaratu. (Purbaratu's fiancé.Tunangannya Purbaratu)

[8]

Siswa : Bu, ai mole the naon?

Guru : Karang

(tahi lalat)

Data 6, 7, dan 8 jelas menunjukkan bahwa guru langusng menerjemahkan kata dan kalimat ke dalam bahasa sunda. Selain itu ketika siswa bertanya akan makna suatu kata, guru tidak memberikan tanda atau gesture dan contoh kalimat lain, tapi guru langsung menjawabnya dengan menggunakan bahasa sunda. 
Fungsi yang keempat ialah mengeskpresikan marah, kecewa, serta bahagia.Hal ini terlihat pada saat pemberian hukuman di kelas.Ekspresi marah diberikan oleh guru dan siswa disampaikan dengan Bahasa Sunda.Begitupun sebaliknya ekpresi bahagia dan bercanda ditunjukkan dengan menggunakan bahasa Sunda oleh guru dan siswa.

[9]

Guru : I like that! Give applause please!

Siswa X : Wow! You did great job!

Siswa B : bisaan euy, Keren lah!

(keren, kamu hebat!)

[10]

Siswa $\quad: \mathrm{Bu}, \mathbf{Y}$ niron wae ka abi!

(Bu, Y nyontek terus pada saya)

Guru $\quad: Y$, teu kenging niron atuh. Kerjakeun nyalira.

(Y, tidak boleh nyontek!Kerjakan sendiri!)

[11]

Guru : F, Stop talking and go out right now!

Siswa : naon bu?

(apa bu?)

Guru : eeh, kaluar, kaluar! Ngaganggu wae nu keur diajar!

(eeh, keluar, keluar! Menganggu yang sedang belajar saja!)

Pemberian pujian, mengungkapkan kesal dan marah dilakukan guru dengan menggunakan bahasa Sunda. Pada data 9, 10, dan 11 ketika guru mengungkapkan perasaannya menggunakan bahasa Inggris siswa tidak paham, maka guru pun langsung menggunakan bahasa sunda sebagai respon pada ketidakpahaman siswa akan apa yang telah ia ucapkan.

\section{b. Alasan penggunaan Bahasa Sunda dalam pembelajaran Bahasa Inggris:}

Untuk menjawab pertanyaan penelitian yang kedua ini peneliti menggunakan wawancara sebagai instrumen penelitian. Wawancara dilakukan pada siswa dan guru. Hasil wawancara menunjukkan bahwa guru dan siswa memiliki alasan yang sangat kuat dalam penggunaan Bahasa Sunda pada pengajaran Bahasa Inggris.

Pertama, untuk memberikan kenyamanan pada siswa agar berani dan aktif di kelas maka guru mempersilahkan siswa untuk mengunakan Bahasa Sunda. Guru sangat paham sekali dengan kondisi siswanya, dengan lingkungan yang jauh dari perkotaan maka kebutuhan siswa untuk belajar bahasa Inggris sangatlah rendah, maka ketika guru menggunakan bahasa Inggris dikelas siswa terlihat bingung, tegang, dan terkadang tujuan pembelajaran pun tidak tercapai dengan baik. Oleh karena itu untuk memberikan rasa nyaman pada siswa untuk belajar bahasa Inggris, guru pun menggunakan bahasa sunda pada proses belajar mengajar. 
Selain itu, karena kepercayaan diri siswa kurang dalam menggunakan bahasa Inggris di kelas sehingga ketika guru memberikan perintah untuk tampil di depan kelas, bertanya, atau pun merespon guru, maka siswa pun menjadi pasif bahkan mereka hanya berdiam diri tanpa memberikan kontribusi aktif di kelas. Begitu pun sebaliknya, ketika siswa diberi kesempatan untuk tampil dengan menggunakan dua bahasa (Bahasa Inggris dan Bahasa Sunda) siswa pun bersemangat dan mau terlibat aktif pada kegiatan belajar mengajar.

Kedua, penggunaan Bahasa Sunda menjadi kebiasaan yang digunakan dalam kehidupan sehari-hari siswa, maka penggunaan Bahasa Sunda dijadikan alasan untuk memudahkan memahami Bahasa Inggris.Guru di sekolah tersebut mengungkapkan bahwa siswa sangat asing dengan bahasa Inggris, kondisi lingkungan serta latar belakang orang tua mempengaruhi siswa untuk tidak tertarik mempelajari bahasa asing. Dengan demikian, guru memilih menjelaskan materi langsung pada intinya dengan menggunakan bahasa sunda. Guru juga merasa proses belajar mengajar menjadi kurang efektif ketika menggunakan Bahasa Inggris penuh, siswa nya tidak paham dan guru harus menerjemahkan ke dalam bahasa sunda.

Ketiga, untuk menghindari kesalahpahaman makna Bahasa Inggris maka guru dan siswa menggunakan Bahasa Sunda sebagai alat penerjemah Bahasa Inggris.Pada pelaksanaan kegiatan belajar mengajar tidak jarang guru menerjemahkan bahasa Inggris ke dalam bahasa Sunda. Hal ini dikarenakan siswa tidak memiliki kamus Bahasa Inggris-Bahasa Indonesia yang dapat mereka gunakan untuk mencari makna kata-kata yang sukar untuk dipahami.Guru juga berpendapat bahwa gesture kurang dapat membantu siswa memahami kata atau kalimat dalam Bahasa Inggris.pemberian contoh dengan menggunakan kata ganti atau sinonim juga telah guru lakukan, namun tetap saja siswa lebih memahami kata yang diterjemahkan guru ke dalam bahasa sunda.

\section{c. Pandangan siswa terhadap penggunaan Bahasa Sunda dalam pembelajaran Bahasa Inggris:}

Untuk menjawab pertanyaan penelitian ini, peneliti menggunakan kuesioner pada siswa.

Tabel 1:

Persepsi Siswa terhadap penggunaan Bahasa Sunda pada Pembelajaran Bahasa Inggris

\begin{tabular}{|c|c|c|c|c|c|c|}
\hline No & Statements & SA & $\mathbf{A}$ & $\mathbf{N}$ & DA & SDA \\
\hline 1 & $\begin{array}{l}\text { I like when my English } \\
\text { teacher tend to use Bahasa } \\
\text { Sunda as the medium } \\
\text { instruction }\end{array}$ & $35 \%$ & $37 \%$ & & $28 \%$ & \\
\hline
\end{tabular}




\begin{tabular}{|c|c|c|c|c|c|c|}
\hline 2 & $\begin{array}{l}\text { The use of English only in the } \\
\text { classroom can improve my } \\
\text { English standard. }\end{array}$ & & $12 \%$ & $5 \%$ & $37 \%$ & $46 \%$ \\
\hline 3 & $\begin{array}{l}\text { English teacher are good } \\
\text { examples if they only use } \\
\text { English in the classroom. }\end{array}$ & & $35 \%$ & $50 \%$ & $15 \%$ & \\
\hline 4 & $\begin{array}{l}\text { It is fun to listen to my friends } \\
\text { speaking English in the class. }\end{array}$ & & & $20 \%$ & $38 \%$ & $42 \%$ \\
\hline 5 & $\begin{array}{l}\text { I will not be upset if my } \\
\text { friends also speak Bahasa } \\
\text { Sunda in the class. }\end{array}$ & $12 \%$ & $42 \%$ & $25 \%$ & $21 \%$ & \\
\hline 6 & $\begin{array}{l}\text { Given the choice, I prefer } \\
\text { using English-only in English } \\
\text { classes instead of mixing it } \\
\text { with Bahasa Sunda. }\end{array}$ & $35 \%$ & $50 \%$ & & $15 \%$ & \\
\hline 7 & $\begin{array}{l}\text { If my English teacher uses } \\
\text { English to teach English, I } \\
\text { will be excited. }\end{array}$ & & & $32 \%$ & $18 \%$ & $50 \%$ \\
\hline 8 & $\begin{array}{l}\text { The use of Bahasa Sunda can } \\
\text { make me master in English } \\
\text { well. }\end{array}$ & $32 \%$ & $25 \%$ & $23 \%$ & $20 \%$ & \\
\hline 9 & $\begin{array}{l}\text { I don't understand if my } \\
\text { teacher and friend speak } \\
\text { English in the classroom. }\end{array}$ & $35 \%$ & $27 \%$ & & $38 \%$ & \\
\hline 10 & $\begin{array}{l}\text { I will not be excited when my } \\
\text { teacher use English fully in } \\
\text { the classroom. }\end{array}$ & $50 \%$ & $12 \%$ & $38 \%$ & & \\
\hline
\end{tabular}

(Haryanto, Sulistiyo, Khairani, \& Wulan, 2016)

Berdasarkan data pada Tabel 1,72\% siswa menyukai penggunaan Bahasa Sunda dalam pemberian instruksi atau perintah di kelas, akan tetapi $83 \%$ siswa yakin bahwa penggunaan Bahasa Inggris secara penuh dapat meningkatkan kualitas Bahasa Inggris mereka. Hal ini juga didukung dengan $35 \%$ siswa merasa bahwa guru Bahasa Inggris mereka ialah contoh terbaik dalam pembelajaran Bahasa Inggris, tentunya jika guru menggunakan Bahasa Inggris secara penuh di kelas.

Selanjutnya $80 \%$ siswa merasa tidak suka saat mendengar temantemannya menggunakan Bahasa Inggris di kelas, bahkan 54\% siswa tidak merasa khawatir jika dalam pembelajaran Bahasa Inggris teman-teman mereka menggunakan Bahasa Sunda dan $71 \%$ siswa pun tidak paham saat mendengar guru dan siswa lainnya berbicara bahasa Inggris. Selain itu 62\% siswa tidak bahagia jika guru mereka menggunakan Bahasa Inggris penuh di kelas. 
Ketika diberikan pilihan 85\% siswa setuju untuk menggunakan Bahasa Inggris di kelas walaupun dicampur dengan Bahasa Sunda. Mereka memerlukan bahasa ibu mereka dalam kegiatan belajar mengajar, haldemikian juga terlihat bahwa 68\% siswa tidak setuju jika guru mereka menggunakan Bahasa Inggris secara penuh di kelas. Dengan menggunakan dua bahasa yaitu Bahasa Sunda dan Bahasa Inggris secara bersamaan 57\% siswa setuju bahwa mereka lebih paham dan dapat menguasai Bahasa Inggris dengan baik.

Melihat hasil kuesioner diatas dapat disimpulkan bahwa siswa memiliki pandangan yang positif terhadap penggunaan Bahasa Sunda dalam pengajaran Bahasa Inggris. Siswa bahkan lebih menyukai jika guru tidak menggunakan Bahasa Inggris secara penuh di kelas dan perlu dicampur dengan menggunakan Bahasa Sunda.

\section{KESIMPULAN}

Fungsi Bahasa Sunda pada proses kegiatan belajar mengajar bahasa Inggris ialah untuk pemberian instruksi, pemberian motivasi, penjelasan kosakata dan materi ajar, menunjukan ekspresi marah, kecewa, dan bahagia. Selanjutnya, alasan penggunaan Bahasa Sunda dalam pembelajaran Bahasa Inggris karena ingin memberikan rasa nyaman dan kemudahan ketika berkomunikasi dan berinteraksi baik dengan guru maupun teman sejawat, serta untuk menghindari kesalahpahaman makna baik dalam komunikasi biasa ataupun dalam pemeberian materi ajar.Siswa menunjukan persepsi positif terhadap penggunaan Bahasa Sunda dalam pembelajaran Bahasa Inggris di kelas.

\section{DAFTAR PUSTAKA}

Alshehri, E. (2017). Using Learners' First Language in EFL Classrooms. LAFOR Journal of Language Learning, 3(1), 20-33. https://doi.org/10.22492/ijll.3.1.02

Brown, D. (2007). Principes of Language Learning and Teaching Fifth Edition (5th ed.). New York: Pearson Education.

Buyukyazi, M. S. \& M. (2011). 1st International Conference on Foreign Language Teaching and Applied Linguistics Politics of English in the Arabian Gulf 1st International Conference on Foreign Language Teaching and Applied Linguistics May 5-7 2011 Sarajevo. Conference on Foreign Language Teaching and Applied Linguistics, (1989), 60-66. https://doi.org/10.1007/s12555-012-0213-z

Ghorbani, A. (2011). First language use in foreign language classroom discourse. Procedia - Social and Behavioral Sciences, 29, 1654-1659. 
https://doi.org/10.1016/j.sbspro.2011.11.408

Harmer, J. (2007). The Practice of English Language Learning. England: Pearson Education Limited.

Haryanto, E., Sulistiyo, U., Khairani, M., \& Wulan, R. (2016). Indonesian or English? EFL Student Teachers' Preference and Perception on the Language Use in the Classroom. IJEE (Indonesian Journal of English Education), 3(1), 46-59. https://doi.org/10.15408/ijee.v3i1.3941

Khati, A. R. (2012). When and Why of Mother Tongue Use in English Classrooms. Journal of NELTA, 16(1-2), 42-51. https://doi.org/10.3126/nelta.v16i1-2.6128

Maharani, T., \& Astuti, E. S. (2018). Pemerolehan Bahasa Kedua dan Pengajaran Bahasa dalam Pembelajaran BIPA. Jurnal Babasa Lingua Scientia, 10(1), 121-142. https://doi.org/10.21274/1s.2018.10.1.121-142

Miles, M. B., Huberman, ;A Michael, \& Saldana, J. (2014). Qualitative Data Analyisis: A Mathods Sourcebook (3rd ed.). United State of America: SAGE Publications, Inc.

Pardede, P. (2012). The Use of Native Language in ELT Classrooms. Jurnal Dinamika Pendidikan, 5(April), 19-23.

Romero, Y., \& Manjarres, M. P. (2017). How Does the First Language Have an Influence on Language Learning? A Case study in an English ESL Classroom. English Language Teaching, 10(7), 123. https://doi.org/10.5539/elt.v10n7p123

Setyadi, A. C., \& Salim, M. S. (2013). Pemerolehan Bahasa-Kedua. At Ta'dib, 8(2), 75. https://doi.org/10.21111/at-tadib.v8i2.504

Syahid, A. H. (2015). Bahasa Arab Sebagai Bahasa Kedua (Kajian Teoretis Pemerolehan Bahasa Arab Pada Siswa Non-Native). ARABIYAT : Jurnal Pendidikan Bahasa Arab Dan Kebahasaaraban, 2(1), 86-97. https://doi.org/10.15408/a.v2i1.1797

Zakaria, F. (2017). the Role of First Language in Efl Classroom. Jurnal Ilmiah Didaktika, 13(2), 373-383. https://doi.org/10.22373/jid.v13i2.484 